\title{
PROJETO CAMPO FÁCIL - UEL: ASSISTÊNCIA TÉCNICA E DIFUSÃO DE TECNOLOGIA AOS AGRICULTORES FAMILIARES DO MUNICÍPIO DE LONDRINA - PR
}

\author{
Eli Carlos de Oliveira ${ }^{1}$ \\ José Roberto Pinto de Souza ${ }^{2}$ \\ Ésio de Pádua Fonseca ${ }^{3}$ \\ Fernando Modos Veiga Dias ${ }^{4}$ \\ Daniel Lavorente de Oliveira
}

\section{RESUMO}

Projetos de extensão executados por alunos de agronomia permite uma proximidade entre estudantes e produtores rurais. O objetivo do projeto UEL Campo Fácil é prestar assessoria agronômica através de estudantes do curso de agronomia da Universidade Estadual de Londrina aos agricultores familiares de Londrina e com isso aumentar a produtividade, incrementar sua renda, melhorar a qualidade de vida e proteger o meio ambiente. O projeto disponibiliza professores e estrutura física e intelectual. O início dos trabalhos dá-se com diagnóstico detalhado das propriedades que são discutidos em reuniões com professores e estudantes, e encaminhado propostas de soluções para serem aplicadas nas propriedades. A avaliação do projeto é realizada por reuniões periódicas e relatórios semestrais. Melhorias nas práticas de colheita, como separação dos frutos de café maduros dos verdes proporcionaram aumento da qualidade do produto. Foram deslumbradas novas oportunidades para melhoria da qualidade de vida dos produtores através do desenvolvimento da agroindústria e artesanato, aproveitamento de resíduos orgânicos, preservação e recuperação de mananciais e minas d'água como também na conservação do solo.

Palavras-chave: assentamento rural, extensão rural, produtividade.

\footnotetext{
${ }^{1}$ Professor do Departamento de Agronomia da Universidade Estadual de Londrina (UEL). Coordenador do projeto UEL - Campo Fácil. E-mail: elioliveira@uel.br.

${ }_{2}$ Professor do Departamento de Agronomia da Universidade Estadual de Londrina (UEL).

${ }^{3}$ Professor do Departamento de Agronomia da Universidade Estadual de Londrina (UEL).

${ }^{4}$ Graduando do curso de Agronomia da Universidade Estadual de Londrina e participantes do projeto (UEL)

- Campo Fácil.

${ }^{5}$ Graduando do curso de Agronomia da Universidade Estadual de Londrina e participantes do projeto (UEL)

- Campo Fácil.
} 


\title{
CAMPO FÁCIL PROJECT - UEL: TECHNICAL ASSISTANCE AND TECHNOLOGY DISSEMINATION TO FARMERS FAMILY OF LONDRINA MUNICIPALITY - PR
}

\begin{abstract}
Extension projects carried out by students of agronomy allow closeness between students and farmers. The objective of the UEL Campo Fácil project is to provide agronomic advice through students of the agronomy course of the Londrina State University to family farmers in Londrina and thereby increase productivity, increase income, improve quality of life and protect the environment. The project provides teachers and physical and intellectual structure. The beginning of the work is done with detailed diagnosis of the properties that are discussed in meetings with teachers and students, and forwarded proposals of solutions to be applied in the properties. Project evaluation is carried out through periodic meetings and semi-annual reports. Improvements in the harvesting practices, such as separation of the mature coffee fruits from the greens, provided an increase in product quality. New opportunities for improving the quality of life of producers were dazzled by the development of agribusiness and handicrafts, use of organic waste, preservation and recovery of water sources, as well as soil conservation.
\end{abstract}

Keywords: rural extension, rural settlement, yield.

\section{INTRODUÇÃO}

A forma fundamental e eficiente de comunicação de novas tecnologias geradas pela pesquisa e transmitida ao agricultor é através da assistência técnica e extensão rural, isto porque propicia difusão de conhecimentos diversos e essenciais ao desenvolvimento rural, em especial no desenvolvimento de atividades agropecuárias (DIAS, 2008).

No Brasil o modelo produtivo agropecuário adotado foi implantado na década de 1960 uma ação conjunta e organizada pelo tripé ensino, pesquisa e extensão. Ou seja, as universidades, órgãos de pesquisa e de extensão rural foram os responsáveis pela introdução de tecnologias voltadas para a utilização intensiva de insumos e máquinas, com o objetivo do aumento da produtividade (CARVALHO, 1992; LISITA, 2008).

$\mathrm{Na}$ década de 60 , apenas $10 \%$ dos municípios Brasileiros contavam com o serviço de extensão rural, prestado pela Empresa Brasileira de Assistência Técnica e Extensão Rural (EMBRATER). Mais tarde, em 1980 a extensão rural chegou a $77,7 \%$ (LISITA, 2008).

Hoje, o desafio dos órgãos de pesquisa, universidades e movimentos sociais é o de criar estratégias para colocar em prática metodologias participativas da assistência técnica rural, que incluam os agricultores familiares desde a concepção até a aplicação das tecnologias, transformando-os em agentes no processo, valorizando seus conhecimentos e respeitando seus anseios (LISITA, 2008).

A partir dos anos 90 observa-se um crescente interesse pela agricultura familiar no Brasil. Este interesse se materializou em políticas públicas, como o PRONAF (Programa Nacional de Fortalecimento da Agricultura Familiar) e na criação do MDA (Ministério do Desenvolvimento Agrário), além do revigoramento da Reforma Agrária. 
A agropecuária familiar no Brasil possui importância fundamental na geração de renda, empregos e principalmente na produção de alimentos. Atualmente, há cerca de 4,3 milhões de estabelecimentos agropecuários de caráter familiar no Brasil, correspondendo a $80,3 \%$ do total e uma população de 14 milhões de pessoas (IBGE, 2006). O A agricultura familiar cria oportunidades de trabalho local, reduz o êxodo rural, diversifica a atividade econômica e promove o desenvolvimento de pequenos e médios municípios (RODRIGUES, 1997; MIRANDA et al., 2016).

O Censo Agropecuário do IBGE de 2006, referente ao Estado do Paraná, revelou a existência de 302.907 propriedades rurais com agricultura familiar que ocupam um total de 4.249 .882 hectares $(27,8 \%)$, e 68.144 propriedades que ocupam 11.036 .652 hectares $(72,2 \%)$ com agricultura não familiar.

O município de Londrina é um grande centro consumidor distante de alguns distritos até $80 \mathrm{~km}$. Isso faz com que os pequenos produtores tenham dificuldades no acesso aos meios de produção necessários como a compra de insumos, assistência técnica, agências bancárias, a comercialização. Consequentemente, isso incide na diminuição e redução da produtividade, e possivelmente na renda baixa dessa produção rural. Mesmo pequena em relação à população total, isso irá refletir no índice de desenvolvimento humano (IDH) do município que é de 0,824 e que apresenta índices mais altos do país. Os distritos mais distantes da área urbana, como os de Lerroville e a comunidade de Guairacá, apresentam um IDH de 0,683 e chegam a apresentar índices comparados aos mais baixos do Estado (IBGE, 2015).

A agricultura familiar tem uma ação multifuncional por que além de produzir alimentos e matérias-primas, gera mais de $80 \%$ da ocupação no setor rural e favorece o emprego de práticas produtivas ecologicamente mais equilibradas, como a diversificação de cultivos, o menor uso de insumos industriais e a preservação do patrimônio genético (RIVERA; QAMAR, 2003; SEPULCRI, 2005; SWANSON, 2006).

Os projetos de extensão executados por universidades permitem o contato direto dos estudantes com a realidade e os problemas enfrentados pelas comunidades rurais. A aproximação entre comunidade acadêmica e pequenos agricultores beneficia tanto a universidade, através da complementação na formação acadêmica dos alunos quanto dos agricultores, através da assessoria técnica.

O projeto de extensão do curso de agronomia da Universidade Estadual de Londrina foi idealizado para prestar assessoria agronômica aos agricultores familiares do município de Londrina, Paraná, com intuito maior de propiciar o aumento da produtividade, o incremento da renda, a melhoria da qualidade de vida e na proteção ao meio ambiente.

\section{METODOLOGIA}

O projeto UEL Campo Fácil foi desenvolvido por um grupo de docentes e discentes do curso de Agronomia da Universidade Estadual de Londrina (UEL) em 2009 para assistir os pequenos agricultores rurais do município de Londrina, Paraná.

O grupo de docentes é formado por quatro docentes, um coordenador e três tutores, e outro grupo composto por oito acadêmicos do curso de agronomia, quatro do $3^{\circ}$ ano e mais quatro do $4^{\circ}$ ano do curso de agronomia. A seleção dos acadêmicos ocorre sempre no final do primeiro semestre do ano.

Os agricultores familiares selecionados a participar do projeto devem atender a Lei Federal no 11.326, de 24 de julho de 2006, ou seja, ser detentor de área não superior a dois módulos fiscais do INCRA; possuir renda bruta agropecuária anual prevista de até $\mathrm{R} \$ 45.000,00$ (Quarenta e Cinco Mil Reais), e 
possuir no mínimo $80 \%$ (Oitenta por cento) da receita bruta anual proveniente de atividade agropecuária.

Os agricultores selecionados recebem visitas periódicas dos estudantes para detecção dos problemas agronômicos de cada propriedade. O coordenador do projeto visitou distritos rurais de Londrina, sempre na busca de selecionar a comunidade que melhor viesse atender os objetivos do projeto. Várias áreas foram descartadas, pois não apresentavam quantidade significativa de produtores e havia dificuldade de acesso, o que poderia inviabilizar o planejamento de transporte dos alunos e docentes.

Os professores participantes do projeto desenvolvem atividades como seleção, orientação e acompanhamento das atividades dos estudantes, palestras e a realização de relatórios. Cada professor tutor orienta dois acadêmicos.

Os agricultores selecionados recebem visitas periódicas (semanalmente) dos estudantes para detecção dos problemas agronômicos de cada propriedade. Após o estudo de cada caso ou problema detectado a campo, o grupo técnico, docentes e estudantes se reúne e propõe recomendações para o agricultor para amenizar ou solucionar o problema. Todas as propriedades rurais visitadas são monitoradas para verificar as respostas às recomendações propostas pelo grupo. São realizadas reuniões periódicas para verificar o andamento do projeto junto aos agricultores selecionados.

O início dos trabalhos de assistência técnica pelos estudantes se dá com a elaboração de um diagnóstico detalhado da propriedade, fundamental para subsidiar o plano de ação individual e do grupo. E realizado pelo grupo de alunos nas primeiras visitas às propriedades rurais. O diagnóstico não deve ser muito extenso, devendo contemplar informações básicas que sustentem a elaboração de um planejamento de atividades para propriedade assistida. Os modelos de diagnósticos para cada produtor são desenvolvidos a partir da realidade local como, por exemplo, a as atividades a serem desenvolvidas; os objetivos a serem alcançados nos períodos pré-definidos, conforme indicadores estabelecidos; os efeitos alcançados, tais como renda líquida gerada, reduções de custos relativos e incrementos de lucros da atividade; os impactos resultantes da participação do produtor e no projeto, referentes ao desenvolvimento, satisfação e bem-estar.

Todos os custos envolvidos na implantação das novas técnicas são de responsabilidade do proprietário rural. A Universidade se responsabiliza pelos custos de deslocamento da equipe até as propriedades rurais, como também libera os seus laboratórios e técnicos para o desenvolvimento do projeto. A instituição garante também seguro aos alunos envolvidos no projeto.

Os resultados do projeto vão desde o nível de satisfação do produtor com o projeto, quanto a evolução dos indicadores de desempenho e o incremento de renda do produtor, principal resultado a ser medido como diferencial oferecido pelo projeto. Avaliação dos resultados práticos é feita através de relatórios e reuniões de avaliação do grupo envolvido, bem como com a apresentação de trabalhos técnicos e divulgados em eventos de extensão locais, regionais, estaduais e nacionais.

\section{RESULTADOS}

Os alunos do curso de Agronomia realizaram levantamento de dados através de georreferenciamento das propriedades, históricos das culturas, práticas e manejos adotados, quantidade e dose de produtos utilizados, colheita, beneficiamento e comercialização dos produtos. Esta integração foi proposta com objetivo de propiciar benefícios mútuos, os pequenos proprietários se beneficiam 
das informações técnicas levadas pelos alunos, e os alunos aplicam todo o seu conhecimento técnico adquiridos na sala de aula.

Os dados coletados evidenciaram no primeiro momento que boa parte dos produtores produzia e comercializava seus produtos sem nenhum acompanhamento e orientação técnica, o que resultava nas baixas produções, produtividades e preços de comercialização que proporcionavam baixa renda familiar.

A comunidade de pequenos agricultores da Fazenda Barranco Vermelho

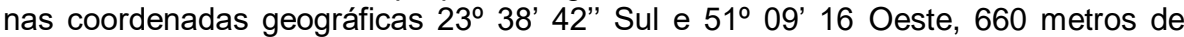
altitude, distrito de Guaravera, município de Londrina, foi escolhida para participar do projeto em 2011.

Esta comunidade foi selecionada por que grande parte dos agricultores participantes é originada do meio agrário, ou seja, eram trabalhadores rurais que por muitos anos prestaram serviços para uma grande propriedade. Em função dos seus esforços, qualidade dos serviços, empenhos, dedicações, os agregados receberam de forma gratuita a casa para morar e a posse de suas propriedades, bem como auxílio para a implantação de suas lavouras.

No ano de 1997, o proprietário da Fazenda Barranco Vermelho selecionou entre os seus funcionários, 36 pessoas que mais contribuíram para a sua empresa e como forma de agradecimento e satisfação pelos serviços prestados receberem lotes de tamanho mínimo de um (1) e máximo de dois (2) alqueires paulistas.

Além do terreno, conforme o interesse de cada agregado, o antigo patrão deu total auxílio financeiro e logístico, no sentido de preparar o solo para plantio, aquisição de sementes e mudas, fertilizantes e demais insumos.

Em menos de 15 anos de existência da comunidade, dos 36 pequenos proprietários que receberam a posse de suas terras, apenas 10 deles ainda permaneceram nas suas propriedades. As demais propriedades foram comercializadas com os vizinhos remanescentes ou com outros proprietários da região.

Foram realizadas alterações simples nas práticas adotadas para a colheita e beneficiamento do café, que proporcionaram a comercialização do café em bolsas de mercadorias, via pregões eletrônicos, e aumentaram a receita e melhoraram a qualidade de vida dos assentados.

A manutenção da viabilidade da pequena propriedade familiar é necessária alteração na forma de condução da atividade. Segundo o estudo realizado, os produtores obtiveram uma margem de lucro maior este ano por conta do preço atípico que o café obteve na safra 2011/2012. Quando se compara os preços obtidos nas safras de 2009, 2010 e 2011, a margem de lucro obtida na atividade cafeeira foi pequena, comprometendo a perpetuação da viabilidade econômica da propriedade, pois aumenta os riscos de prejuízo. Se o produtor aumentar a produtividade e diminuir os custos de sua produção, a sua renda será incrementada viabilizando a cafeicultura na área.

Verificou-se que as lavouras de café apresentavam mistura varietal, o que dificultava o manejo e o planejamento de colheita, pragas de raízes, cigarras e bicho mineiro, além de doença como a ferrugem. Há grande irregularidade na maturação dos grãos de café devido à escolha não adequada das variedades, além da morte de folhas e ramos da planta devido ao uso inadequado do herbicida Glyphosate (Figura 2). 
Figura 1 - Problemas detectados na lavoura do café atendida pelo projeto como raízes danificadas por pragas $(A)$, irregularidade de maturação dos frutos colhidos (B) frutos de café caídos no solo (C).

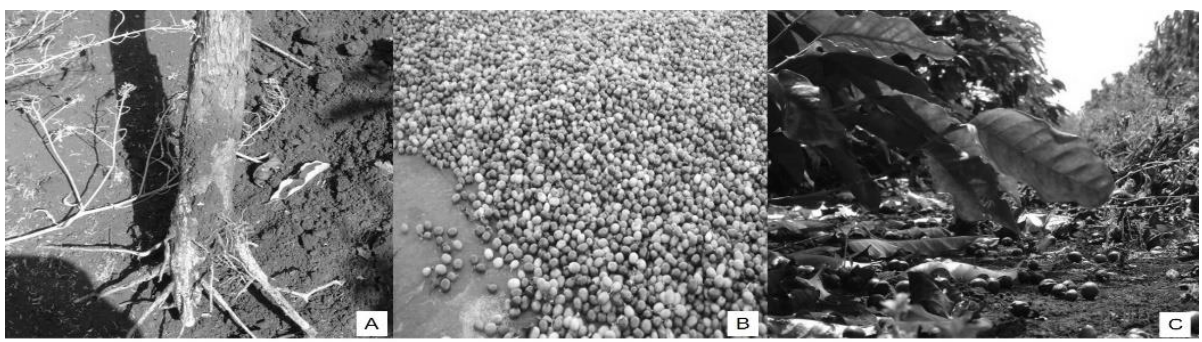

Fonte: Autores (2017)

Os alunos recomendaram aos produtores que colhessem o café no pano e os lavassem para separar os frutos verdes, cerejas e secos, como também secar na forma correta, e obter melhor preço de comercialização (Figura 2). Recomendaramse produtos menos tóxicos ao meio ambiente no controle de pragas e doenças. $\mathrm{O}$ controle manual de plantas invasoras e o uso de adubação verde também foram recomendados. A análise de tecido foliar e de solo das propriedades proporcionaram a adubação mais consciente e adequada para as plantas.

Figura 2 - Recomendações técnicas para o agricultor após o diagnóstico, colheita no pano e mais uniformidade de maturidade dos frutos $(A)$, lavagem para separação dos frutos (B) e secagem (C).

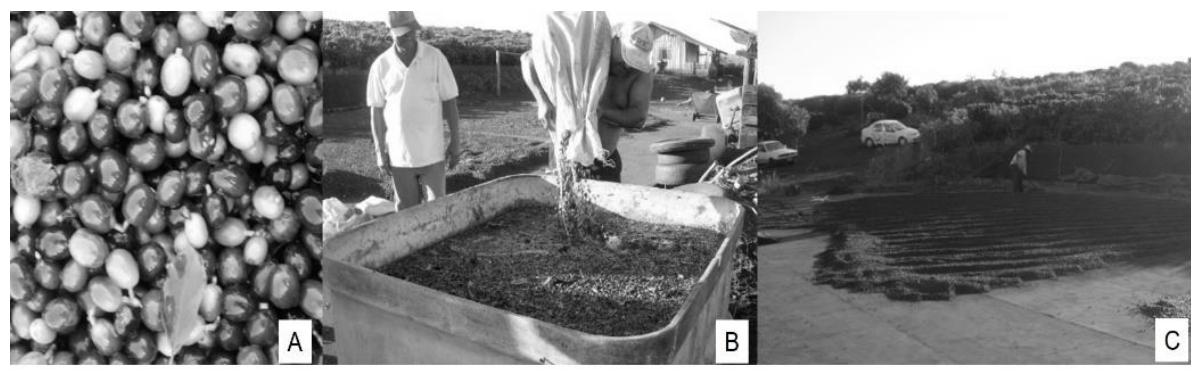

Fonte: Autores (2017)

As adubações foliares das plantas de café com base em análise foliar juntamente com um sistema de diagnóstico e informação completam-se. $\mathrm{Na}$ área estudada, embora o melhor equilíbrio nutricional atingido pelo tratamento com suplementações via fertirrigação com diagnóstico através do DRIS não tenha se manifestado em aumento de produtividade, este equilíbrio promoveu ganhos como maior tamanho de grãos, e principalmente, houve ganho em um atributo importante na saúde vegetal que foi a maior resistência ao ataque de pragas.

O projeto proporcionou aos pequenos agricultores uma palestra aos agricultores sobre o funcionamento da bolsa de mercadoria que põe em contato direto o comprador e o produtor, e ressalta que o emprego da lavagem e separação dos frutos de café em secos, verdes e cerejas obtém maior renda para os produtores no momento da comercialização da produção. 
O projeto UEL Campo Fácil também atua na Vila Rural Esperança localizada no Distrito Irerê, cujas coordenadas geográficas são $23^{\circ} 31^{\prime} 49^{\prime \prime} S$ $51^{\circ} 10^{\prime} 21^{\prime \prime} \mathrm{W}$, formado por 80 propriedades rurais de $500 \mathrm{~m}^{2}$ cada uma. Os estudantes estão coletando informações para realizar os diagnósticos, e posteriormente realizar as recomendações técnicas a cada propriedade ou grupo de propriedades, como também nas áreas de proteção ambiental.

Verificou-se que $57,14 \%$ das propriedades visitadas já produziam e comercializavam algum tipo de produto agrícola de interesse como mandioca e milho, $28,57 \%$ produzem para o próprio consumo sem interesse de comercialização, e $14,29 \%$ do restante não realizam nenhum tipo de agricultura com fins econômicos.

Os estudantes orientaram o produtor José Rodrigues, lote 05, no preparo do solo, na escolha da melhor variedade de milho, espaçamento entre linhas e entre plantas e a quantidade de sementes a ser utilizada na semeadora manual. $O$ produtor obteve uma lavoura com plantas de milho com espigas grandes e bem granadas.

Os diagnósticos evidenciaram no primeiro momento que boa parte dos produtores produzia e comercializava seus produtos sem nenhum acompanhamento e orientação técnica, o que resultava nas baixas produções, produtividades, baixos preços de comercialização proporcionando baixa renda familiar.

As modificações técnicas recomendaram repassar informações simples, como a definição de adubos e doses destes a serem utilizadas nas áreas, assim como orientação de economia, a respeito das formas e modelos mais econômicos para suas aquisições. Recomendações elementares envolvendo desde o preparo do solo, plantio, replantio, escolha de espécies, práticas simples no controle de plantas daninhas, pragas e doenças, melhores critérios e escolha de técnicas que melhorem a qualidade dos produtos obtidos, e que certamente tem interferência direta na comercialização e no retorno econômico foram priorizadas.

Os dados obtidos pelos alunos do Curso de Agronomia da UEL podem inferir que as distribuições de terras para os pequenos produtores rurais devem estar acompanhadas de auxílio financeiro agrícola, e especialmente de acompanhamento técnico de órgãos de extensão rural. Caso esta associação não ocorra poderá haver o insucesso da distribuição de áreas agrícolas, a exemplo do que está ocorrendo nesta comunidade, ou seja, a venda das propriedades rurais doadas.

O projeto oportunizou aos alunos do curso de agronomia da UEL a possibilidade de aplicar os conhecimentos adquiridos nas salas de aulas nas orientações aos pequenos proprietários rurais. Os alunos atuam como elo entre a academia e os pequenos produtores rurais desassistidos pelos órgãos de assistência técnica governamental. Eles atuam nas áreas econômicas (financiamento rural), tecnológicas e sociais junto a esses agricultores.

\section{CONSIDERAÇÕES FINAIS}

Projetos envolvendo assistência técnica tem um papel complementar na formação de estudantes em profissionais com um senso crítico mais apurado. É imprescindível a organização dos produtores e que o mesmo seja assistido por técnicos, instituições públicas de maneira prioritária e permanente, pois 0 desenvolvimento da agricultura familiar certamente vai de encontro aos interesses de setores do agronegócio comprometidos com o complexo agroindustrial da agricultura convencional, detentores de forte poder econômico e político.

O projeto UEL, Campo Fácil não é uma experiência apenas permeada de transitoriedade e problemas de formação e execução. A proposta traz a inovação de um sistema educacional diferente e mais moderno, colocando em discussão uma 
alternativa de prestação de serviços de assistência técnica e extensão rural mais adequada à realidade de pequenos agricultores, de forma a reconhecer suas especificidades e limites de cada produtor.

Assim, o projeto busca tanto inovar institucionalmente a Universidade na maneira de oferecer o ensino, quanto o docente que amplia e diversifica sua forma de lecionar, a partir do momento que propõe colocar em prática, com todos os seus limites, uma modelo de ensino e extensão rural aplicada por seus discentes.

Outra contribuição importante em ser mencionada é o fato de tentar envolver diversos atores sociais no processo e colocá-los no centro de vários debates sobre as potencialidades e limites da busca de consensos sobre as melhores maneiras de intervir para promover o desenvolvimento dos agricultores. Embora esse processo de início não tenha sido tão efetivo e aplicado como esperado por seus idealizadores até o momento.

Até porque, um dos relatos expressos pelos estudantes como dificuldades encontradas, se deve boa parte pela ausência de organizações públicas, no sentido de apoio seja social, político e principalmente econômico, isto tudo diagnosticado pelos estudantes através do contato com os agricultores. Embora alguns aspectos de dificuldades, o maior, ou talvez um dos maiores pontos positivos foi a boa avaliação que os agricultores faziam sobre a presença do apoio dos técnicos dos estudantes e o tipo de serviço que lhes era prestado.

Os primeiros resultados com 0 projeto evidenciam que pequenos produtores rurais necessitam de assistência técnica e também devem estar acompanhados de auxílio financeiro agrícola, o que permitirá o sucesso sustentável da sua atividade e principalmente sua permanência no campo.

Por fim, são nítidos os bons resultados em se agregar, o conhecimento teórico e a prática. Os saberes pedagógicos são indispensáveis aos estudantes, entretanto, saber onde e como aplica-los é importantíssimo no processo de formação de um profissional mais completo. Fica evidente que é no interior das práticas e contato com agricultores fora da sala de aula, elementos curriculares constitutivos próprios dos cursos de formação, que se apresenta grande parte das possibilidades de articulação entre prática e teoria.

Do início até a data agora já passaram pelo projeto 25 estudantes que entendera a proposta do projeto. Ou seja, programar novas formas de aulas, como momentos estanques, separados da formação como um todo, de maior envolvimento do acadêmico com a vida universitária, produzindo um novo significado a essas práticas a partir do entendimento da importância da construção dos saberes da experiência em uma perspectiva do conhecimento formal.

Temos a total convicção que através dessa modalidade, os acadêmicos podem desenvolver em situações-problema concretas, sendo a própria natureza do objeto, norteando auxiliando no processo de formação profissional. O fato é que toda esta experiência prática que precede a formação servirá nas tomadas de decisões e discussões, seja com o professor ou até mesmo com os futuros equipes de trabalho.

O propósito abordado no projeto prega também como um desafio para eles, conciliar estudo e trabalho, pois possibilita reflexões, no sentido dearticular teoria e prática. Uma grande parcela dos estudantes prestes a concluírem a graduação e outros já graduados não possui essa referência do mundo do trabalho, onde as competências são construídas. Em relação à formação continuada, por outro lado, percebe-se muitas vezes que esta tem assumido um caráter fragmentado em cursos de curta duração, não articulando essa formação com as experiências já desenvolvidas pelos professores, com questões reais do seu cotidiano. Assim o discurso distante da prática pedagógica reforça o conceito da distinção entre o saber e o fazer. 
Para que os produtores venham adotar as novas técnicas agronômicas é necessário que haja alteração radical nas culturas, que deve iniciar com a reforma dos cafezais. Para que isto aconteça, deve-se buscar um aumento de renda com as operações que vão da colheita a comercialização, e com esse aumento os agricultores poderão substituir paulatinamente as plantas deficientes por variedades mais produtivas.

\section{REFERÊNCIAS}

CARVALHO, J. C. M. O desenvolvimento da agropecuária brasileira: da agricultura escravista ao sistema agroindustrial. Brasília: EMBRAPA-SPI, 1992.

DIAS, M. M. Políticas públicas de extensão rural e inovações conceituais: limites e potencialidades. Revista Perspectivas em Políticas Públicas, v. 1, n. 1, p. 101114, 2008.

EMBRAPA. Soluções tecnológicas e inovação: a Embrapa no ano internacional da agricultura familiar / Embrapa. - Brasília, DF: Embrapa, 141p. 2014.

GUANZIROLI, C.E.; CARDIM, S.E.C.S. Novo retrato da agricultura familiar - o Brasil redescoberto. Projeto de Cooperação Técnica INCRA / FAO, fevereiro de 2000. Disponível em: <http://incra.gov.br/sade/doc/AgriFam.doc>. Acesso em: 20 ago. 2015

Sistema IBGE de Recuperação Eletrônica (SIDRA). 1970. Disponível em: <http://sidra.ibge.gov.br>. Acesso em: 15 jul. 2015.

LEAL, M. G. F. S.; BRAGA, G. M. Orientação institucional e currículo: a gênese do ensino de extensão rural na Universidade Federal de Viçosa. Cadernos de Ciência \& Tecnologia, Brasília, v. 14, n. 2, p. 269-286, 1997.

LISITA, F.O. Considerações sobre a extensão rural no Brasil. 2008. Disponível em:

<http://www.ambientebrasil.com.br/composer.php3?base=./agropecuario/index.html\& conteudo=./agropecuario/artigos/extensaorural.htm>. Acesso em: 10 jun. 2015.

MIRANDA, E. L.; FIÚZA, A. L. C.; DOULA, S. M. O olhar dos agricultores familiares do município de araponga-MG sobre sua organização social e produtiva: uma discussão pautada nas representações sociais. Extensão Rural, Santa Maria, v. 23, n. 4, p. 07-23, out./dez. 2016. Disponível em:

<https://periodicos.ufsm.br/extensaorural/article/view/21260>. Acesso em: 18 mar. 2017.

RIVERA, W. M.; QAMAR, M. K. Agricultural extension, rural development and the food security challenge. Roma: FAO, 2003. Disponível em:

<http://ftp.fao.org/docrep/fao/006/y5061e/y5061e00.pdf>. Acesso em: 15 jun. 2015.

RODRIGUES, C. M. Conceito de seletividade de políticas públicas e sua aplicação no contexto da política de extensão rural no Brasil. Cadernos de Ciência e Tecnologia, Brasília, v. 14, n. 1, p. 113-154, 1997. 
SEPULCRI, O. Estratégias e trajetórias institucionais da Empresa de Assistência Técnica e Extensão Rural do Paraná (EMATER-PR) Curitiba. Dissertação de mestrado (UFPR), 2005. Disponível em:

<http://dspace.c3sl.ufpr.br/dspace/bitstream/1884/1846/1/od\%3Flio_final>. Acesso em: 01 dez. 2015.

SWANSON, B. E. Extension Strategies for Poverty Alleviation - Lessons from China and India. The Journal of Agricultural Education and Extension, v. 12, n. 4, p. 285-299, 2006.

VEIGA, J. E. Brasil precisa de um projeto. In: ENCONTRO DA SOCIEDADE BRASILEIRA DE ECONOMIA E SOCIOLOGIA RURAL, 36., Poços de Caldas, MG. Anais...Poços de Caldas: Pró-Reitoria de Pós-graduação, 1998. p. 123. 